\title{
Biliary obstruction resulting from Strongyloides stercoralis infection. Report of a case
}

\author{
E Delarocque Astagneau, A Hadengue, C Degott, V Vilgrain, S Erlinger, J P Benhamou
}

\begin{abstract}
Hepatobiliary manifestations of strongyloidiasis are rare. A case is described of biliary obstruction associated with the presence of Strongyloides stercoralis in the duodenal mucosa and $250 \mu \mathrm{m}$ rhabditiform larvae in bile. Biliary obstruction resulted from papillary stenosis, which resolved after treatment with thiabendazole. It is proposed that papillary stenosis may be responsible for obstructive jaundice associated with Strongyloides stercoralis infection, and that strongyloidiasis should be added to the causes of papillary stenosis.
\end{abstract}

Service d'Hépatologie and Unité de Recherches de Physiopathologie Hépatique, INSERM U 24 and Service

d'Anatomie et de

Cytologie Pathologiques,

Hôpital Beaujon, Clichy,

France

E Delarocque Astagneau

A Hadengue

C Degott

V Vilgrain

$S$ Erlinger

J P Benhamou

Correspondence to:

Dr $S$ Eringer, INSERM U-24, Hopital Beaujon, 92118 Clichy Cedex, France.

Accepted for publication

9 August 1993

Figure 1: Photomicrograph of a duodenal biopsy

fragment showing an

inflammatory infiltrate and

rhabditiform larvae of

Strongyloides stercoralis

(arrow).

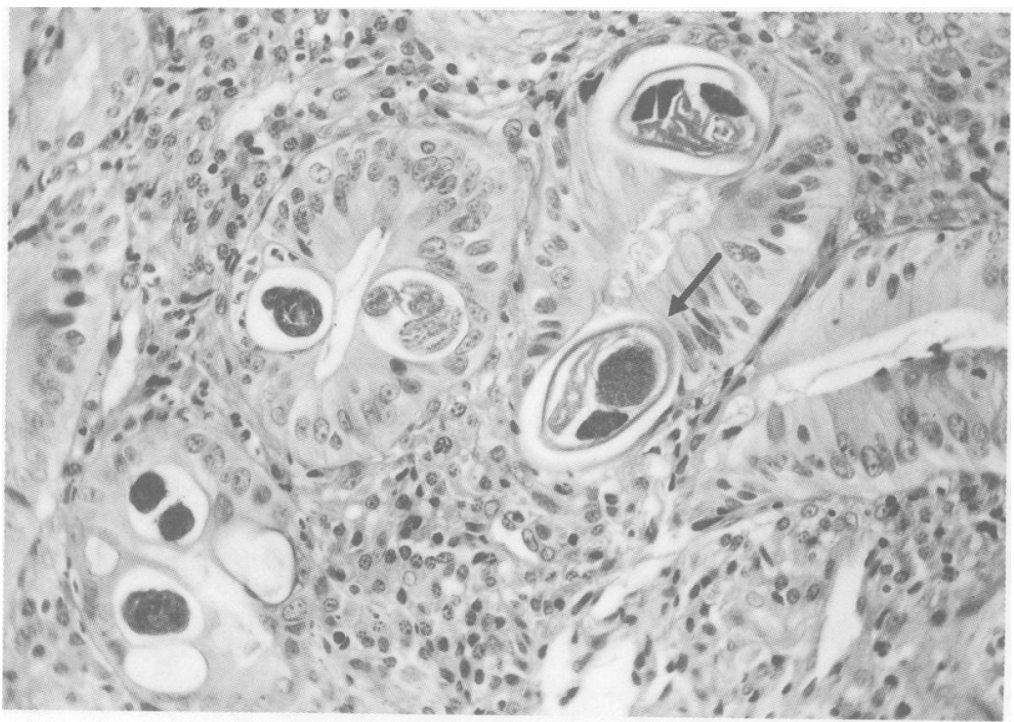

(Gut 1994; 35: 705-706)

epigastric pain, and intermittent pruritus. On physical examination, she was anicteric and afebrile. The liver was enlarged with a smooth surface. Laboratory studies showed a white blood cell count of $7.6 \times 10^{\%} / 1$ with $0.21 \times 10^{9} / 1$ eosinophils, a haemoglobin count of $10.3 \mathrm{~g} / \mathrm{dl}$, and a platelet count of $466 \times 10^{\circ} / 1$. Serum alkaline phosphatase activity was three times the upper normal limit. $\gamma$-Glutamyltransferase was two times the upper normal limit. Serum alanine aminotransferase and aspartate aminotransferase were five times and 2.5 times the upper normal limit, respectively. The total bilirubin was $9 \mu \mathrm{mol} / \mathrm{l}$. Antibodies against HIV 1 and HIV 2 were absent. Antibodies against HTLV 1 were positive. Ultrasound examination showed dilatation of the intrahepatic bile ducts. The common bile duct $(11 \mathrm{~mm})$ and the main pancreatic duct $(4 \mathrm{~mm})$ were also dilated. No biliary stone or pancreatic mass was present. At endoscopic examination, the duodenal mucosa seemed infiltrated and fragile. Histological examination of a duodenal biopsy specimen showed an intense duodenitis resulting from strongyloidiasis (Fig 1). Endoscopic retrograde catheterisation of the papilla was unsuccessful because the papilla could not be identified in the oedematous duodenum. Percutaneous transhepatic cholangiography showed dilatation of the common bile duct and papillary stenosis (Fig 2). Bile samples were obtained and a percutaneous transpapillary

\section{Case report}

A 44 year old Caribbean woman was admitted after a one month history of intermittent fever and abnormal liver tests. She had been living in Paris for many years and had last travelled to the West Indies two years before admission. On admission, she complained of anorexia,

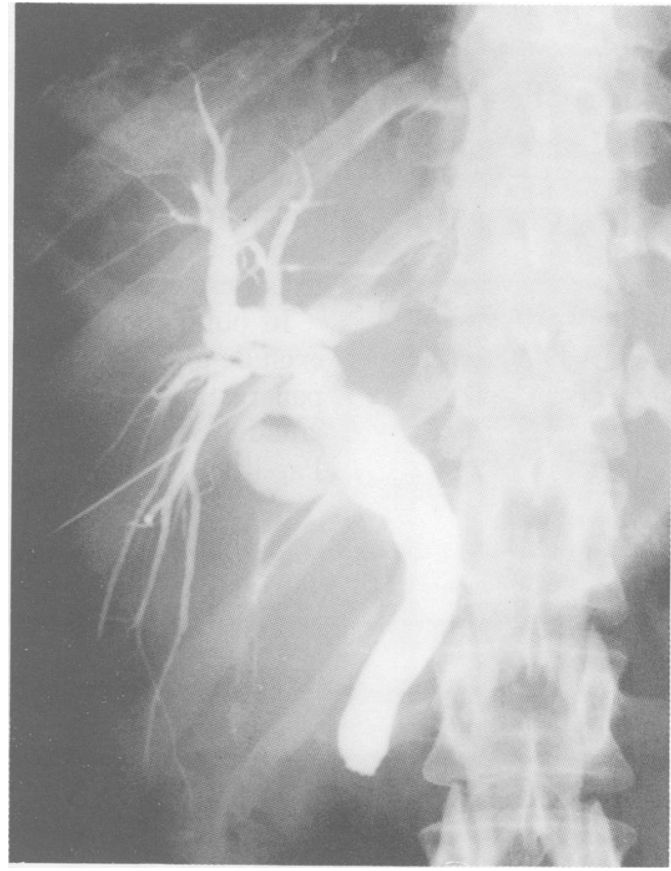

Figure 2: Percutaneous transhepatic cholangiography showing dilatation of intrahepatic bile ducts and common bile duct. There is no passage of contrast material into the duodenum. 
tube was placed. Examination of the bile samples showed alive rhabditiform larvae. Stool examination showed multiple rhabditiform larvae. A liver biopsy was performed; histological examination showed mild portal and lobular inflammation.

The patient received two courses of thiabendazole $(50 \mathrm{mg} / \mathrm{kg})$ one week apart. The transpapillary tube was removed after a total of seven days, when biliary opacification showed normal emptying of the common bile duct.

One month later, the patient was well. Liver tests were normal. Ultrasound examination showed a moderate dilatation of the common bile duct $(7.5 \mathrm{~mm})$ and normal intrahepatic bile ducts. Duodenal biopsy examination showed mild unspecific duodenitis. No parasite was found in the stools or at histological examination of the duodenum.

\section{Discussion}

Hepatobiliary manifestations of strongyloidiasis seem to be rare: no hepatobiliary involvement was mentioned in three series of, respectively, 56, 350, and 1934 infected patients. ${ }^{245}$ Two types of hepatobiliary disorders have been described: granulomatous hepatitis and obstructive jaundice. Granulomatous hepatitis has been reported by Poltera $e t a l^{6}$ in five patients, three of whom had cholestasis without evidence of biliary obstruction. Hennequin et $a l^{7}$ also recently reported a case in whom liver test abnormalities with a normal cholangiography might be attributed to granulomatous hepatitis without biliary obstruction.

Obstructive jaundice and clinical features of acute gall bladder disease have also been described. Filariform larvae have been found in the gall bladder. It has been proposed that jaundice was a result of a mechanical obstruction of the common bile duct. ${ }^{8}$ Mechanical obstruction because of the larvae, however, does not seem probable because of their very small size ( 250 $\mu \mathrm{m})$. Pijls $e t a l^{9}$ described a case of jaundice with stenosis of the distal common bile duct in a patient with Strongyloides stercoralis infection. The stenosis resulted from a pancreatic mass, which resolved after thiabendazole treatment. Subsequently, jaundice disappeared and liver tests were normal. ${ }^{9}$

In our patient, liver biopsy permitted us to exclude granulomatous hepatitis as a cause. No pancreatic mass was detectable. Obstructive jaundice was clearly a result of papillary stenosis. Papillary stenosis was associated with both considerable duodenal inflammation and Strongyloides stercoralis infection. In addition, rhabditiform larvae were isolated from bile specimens. Furthermore, liver tests improved and dilatation of intrahepatic and common bile ducts resolved after thiabendazole treatment. We therefore suggest that papillary stenosis was the consequence of the inflammatory response to massive Strongyloides stercoralis duodenal infection.

Some characteristics of Strongyloides stercoralis are unusual and distinct from those of other intestinal helminths. Firstly, its cycle of autoinfection permits the parasite to reside in the host and have the potential for producing illness for more than 30 years after leaving an endemic area, ${ }^{1}$ and secondly, disseminated infection is known to occur in immunocompromised patients. ${ }^{10}{ }^{11}$ Our patient had anti-HTLV 1 antibodies. HTLV 1 infection seems to be responsible for mild immune impairment. ${ }^{12}{ }^{13}$ Therefore, it is possible that, in our patient, severe strongyloidiasis manifestations were related to this immune state.

We propose that papillary stenosis may be responsible for obstructive jaundice associated with Strongyloides stercoralis infection, and that strongyloidiasis should be considered as one of the causes of papillary stenosis.

1 Scowden EB, Schaffner W, Stone WJ. Overwhelming Strongyloidiasis. An unappreciated opportunistic infection. Medicine 1978; 57: 527-44.

2 Junod C. Anguillulose ou strongyloidose. Quelques aspects d'après 1934 cas diagnostiqués à Paris. Epidémiologie, diagnostic, éosinophilie, traitement. Med Chir Dig 1989; 18: diagnostic, 22 .

3 Genta MR. Global prevalence of strongyloidiasis. Critical review with epidemiologic insights into the prevention of review with epidemiologic insights into the preventio
disseminated disease. Rev Infect Dis 1989; 11: 755-67.

4 Milder JE, Walzer PD, Kilgore G, Rutherford I, Klein M. Clinical features of Strongyloides strecoralis in an endemic area of the United States. Gastroenterology 1981; 80: 1481-8.

5 Bouré P, Taugourdeau A, Barthelemy M, Péquignot-Ricome $\mathrm{H}$, Passeron J, Bouvier JB. Anguillulose. Analyse clinique, biologique et épidémiologique de 350 observations. Presse Med 1981; 10: 679-81.

6 Poltera AA, Katsimbura N. Granulomatous hepatitis due to Strongyloides stercoralis. F Pathol 1974; 113: 241-6.

7 Hennequin C, Pialoux G, Taillet-Bellemere C, Caujolle B, Petite JP. Hyperinfestation à anguillules chez un patient sous corticothérapie: révélation hépatobiliaire. Gastroenterol Clin Biol 1991; 15: 87-8.

8 Kyle LH, McKay DG, Sparling HJ. Strongyloidiasis. Ann Intern Med 1948; 29: 1014 .

9 Pijls NHJ, Yap SH, Rosenbusch G, Prenen H. Pancreatic mass due to Strongyloides stercoralis infection: An unusual manifestation. Pancreas 1986; 1: 90-3.

10 Cruz T, Reboucas G, Rochas H. Fatal Strongyloidiasis in patients receiving corticosteroids. $N$ Engl $\mathcal{F}$ Med 1966; 275 1093-6.

11 Coulaud JP, Vachon F, Poznanski D. Strongyloidose mortelle des sujets immunodéprimés. Revue de la littérature à propos d'un nouveau cas. Med Mal Infect 1982; 12: 66-71.

$12 \mathrm{Kim}$ JH, Durack DT. Manifestations of human T lymphotropic virus type 1 infection. Am $\mathcal{F}$ Med 1988; 84: 919-28.

13 Gallo C. Human retroviruses: a decade of discovery and link with human disease. F Infect Dis 1991; 164: 235-43. 